\title{
Urban Systems, Urbanization Dynamics and Land Use in Italy: Evidence from a Spatial Analysis
}

\author{
Gianni Guastella ${ }^{1}$, Stefano Pareglio ${ }^{2}$ \\ ${ }^{1}$ Department of Agricultural Economics, Catholic University of Sacred Hearth, Piacenza, Italy \\ ${ }^{2}$ Department of Mathematics and Physics, Catholic University of Sacred Hearth, Brescia, Italy \\ Email: giovanni.guastella@unicatt.it
}

Received 28 July 2014; revised 27 August 2014; accepted 22 September 2014

Copyright (C) 2014 by authors and Scientific Research Publishing Inc.

This work is licensed under the Creative Commons Attribution International License (CC BY). http://creativecommons.org/licenses/by/4.0/

c) (i) Open Access

\begin{abstract}
Sustainability of agriculture is challenged by increasing sprawl in urban agglomerations. Under increasing agglomeration economies in large and even medium sized cities, more and more soil is being subtracted to agriculture, depriving agricultural activities of the main production factor. The extent to which the expanding urbanization threatens agricultural development depends on the urban spatial structure, however. In this work it is empirically investigated how the relationship between soil use and soil consumption is shaped by the compactness of a city. For the population of LAU1 (province) main cities in an Italian region (Lombardy), compactness is measured as the density gradient and estimated using Central Business District models. It is found that more compact cities exhibit relatively lower-than-expected soil consumption in the period 1999-2007. Results suggest that agglomeration economies are not enemies of agricultural activities per se. Nonetheless, urbanization needs to be accompanied by urban fringe containment.
\end{abstract}

\section{Keywords}

Land Use, Land Take, Central Business District, Spatial Size of Cities, Spatial Econometrics

\section{Introduction}

The increased awareness on issues related to competition on soil use has driven the attention of policy makers on the future challenges for the European agriculture in the period after the ongoing reform. Sustainability of agriculture is faced by land take which is in turn promoted by increasing urbanization pressures. Such pressures respond not only to socio-demographic trends but also to the need of local administrations to balance current 
expenditures with land use rights (Pareglio, 2013). In this respect, the recent crisis might consolidate and even stimulate this trend in expanding urbanization, especially in small and medium sized cities, where land represents a scarce resource to a lower extent only.

Alongside sustainability of agriculture, in terms of natural resources and, hence, land, consideration is given to the promotion of agricultural diversification with the objective to preserve territorial-specific characters of local agriculture. It is not surprising that academic and policy discussion about land use policies turns central in the discussion about the future of rural development actions in Europe (MIPAAF, 2011; European Commission, 2012). In fact different modes of urban expansion generate differentiated land use patterns with related consequences on agricultures, especially in rural territories at the margins of large urban agglomerations. Central appears, therefore, to establish a connection between the spatial structure of a city and the use of land. Unfortunately land use data are scarce, on the one side. On the other side it is not as easy to provide a classification of urban spatial structure allowing comparison across heterogeneous territories.

In an attempt to produce a territorial characterization of local agricultures, the traditional approach followed in agricultural economics literature has been based on multivariate statistical analysis (Cannata, 1989, 1995; Anania \& Tarsitano, 1995; Cannata \& Forleo, 1998). In these studies, at a national level, the territorial characterization has been pursued by introducing socio-environmental and economic variable in the statistical analysis. In this way, the synthetic output was capable of representing the rural dimension of territories alongside other dimensions closely related to agriculture. Building on this framework, some other studies have proposed detailed classification of territories at a more local, usually regional scale (Esposti, 2000; Gallego, 2004; Vard et al., 2005; Anania \& Tenuta, 2008; Asciuto et al, 2008), frequently with more emphasis on some particular variables to capture local specificities of that territory. The focus of this stream of literature is, however, more on the territorial characterization of the local agro-economic systems. Few is said about the relationship between urban structure and use of resources in general and, more specifically, of land. This is because, on the one side, the methodological approach (multivariate analysis) does not allow moving beyond the evidence suggested by the statistical association. In other words, no causal link can be established between socio-agri-economic characters and land use. On the other side, the output of a multivariate statistical analysis is usually an indicator expressing the degree of urbanization. The relationship between urbanization and land use is then implicitly assumed and not further investigated.

In this paper the issue is approached from a different perspective. By focusing solely on land as a production factor, the work is aimed at constructing a link between land use patterns and urban spatial structure. Although the analysis belongs, in methods and contents, to the urban and regional studies literature, the issues discussed in this work are closely connected with agriculture. Actually, land is a primary input in the agricultural production and, within the more general discussion on sustainability of rural development, urbanization density is likely the best predictor of a variety of territorial characters ultimately connected with agriculture and with rural development, such as, for instance, population density, income, provision of services. In fact, recent research has shown that land use patterns provide the best characterization of the territories in relationship to their urban/rural structure (Pareglio \& Pozzi, 2013). Finally, it is worth to recap that land is the most important resource for which the urban and the rural economy compete in the same territory.

With respect to the methodology, the paper aims at detecting a clear relationship between urban spatial structure and land use/take. Admittedly, the most noteworthy effort in this work is the attempt to estimate the urban structure as the density degree of urbanized area in available land.

Thus, the methodological approach is arranged in a two-step procedure. To approximate urban spatial structure the framework of Central Business District Theory is used and the density gradient estimated. The gradient, a measure of how much urbanization follows a distance-from-the-centre decay is taken and interpreted as a measure of city compactness: when the density gradient is high the city is compact and when the density gradient is low the urban spatial structure is more characterized by sprawl. In the CBD literature, the optimal size of the city is in fact determined by, among others, the consumer preferences on income, housing space and travel time. The optimal size of the city defines an urban fringe separating rural territories from the urbanized area. A lower gradient indicates that the market for agricultural land clears at a lower distance from the centre and hence that, ceteris paribus, the fringe will be located closer to the city, saving peri-urban agricultural land from the urbanization pressures. The measure is also preferred to standard indicators such as population density for two main reasons. Firstly population density says very little about how urbanized areas are distributed in the geographical space of the territory as the same level of population density may in fact correspond to very different 
geographies of urbanization. Secondly, population density highly correlates with urbanization density, which is used as a measure of land use in this research.

Once density gradient is estimated, in the second step, a relationship is built between land use, measured as the urban to total land ratio at the municipality level, land take, measured as the change of this ratio between two periods, and urban spatial structure, described by the density gradient. This is a simple linear relationship and does not in fact contribute assessing any causality between spatial structure and land use/take ${ }^{1}$. Concerning the relevance of this analysis for the agricultural sector the change in land use over time is considered the best proxy of land take based on available data. On the one hand it clearly accounts for the change in urbanization patterns. On the other hand, being urbanized area the complement to one of agricultural area (and assuming that forestry area remains constant), it is also capable of accounting for the dynamic in Usable Agricultural Area (UAA).

The analysis is based on municipality data for the Lombardy region. All data come from the statistical office of the Region and are made available to the public through the geoportal ${ }^{2}$. Available data provide measures of urbanized land and hence allow determining the urbanized to total land ratio and its change over time. More precisely data is available for the years 1999 and 2007. Density gradient is estimated at the provincial level (LAU1 in Eurostat classification) using shares of urbanized area as dependent variable and, for robustness check only, using population density.

Results provide clear evidence that a lower than expected land take is associated with a more compact urban structure. The remaining of the paper is organized as follows. The next section describes the methodology used to estimate the density gradient. Estimation results are presented and discussed in section three together with the figure relating urban structure to land use and land take. Follow conclusion.

\section{Methodology}

This section briefly introduces econometric methodologies used for the empirical analyses. Presented methods are considered the standard workhorse of the economic literature investigating urban spatial structure and the objective is that of measuring the linkage between the degree of urbanization and the distance from the main centre of economic activity (Central Business District).

After seminal works of Alonso (1964), Mills (1967) and Muth (1969) Central Business District (CBD) has become the main reference for theoretical as well as empirical analysis of urbanization patterns. From a theoretical viewpoint the model provides a simple and treatable tool to explain urbanization dynamics and, at the same time, it offers meaningful insights than can be easily tested empirically. Probably this is the reason why, after 40 years, CBD continues to represent a key reference for the analysis of urban structure (McMillen 2006; Paulsen, 2012).

The main implication of a mono-centric urban structure is that urbanization density exponentially declines with increasing distance from CBD. Such prediction can be used, in fact, to explain a variety of phenomena related to urbanization such as, for instance, variation in housing prices, in land values and in population and employment densities.

Rarely studies have considered the share of urbanized area as a proxy for urbanization density. This is probably to be attributed to the lack of consistent and comparable measures of land use. This might appear surprising, at least considering that land use conversion pushed by urbanization pressures is a considerably warning phenomenon related to population and income growth (Brueckner, 2000).

The main objective of CBD literature is the estimation of density gradient, hence the model parameter describing how urbanization density varies at varying distances from CBD. This is a simple but meaningful indicator of urban spatial structure. The coefficient is expected negative and, the larger its magnitude in absolute value, the more compact is the urban structure. Hence low values of the coefficient can be interpreted as evidence of urban sprawl. Following the standard empirical specification in Equation (1), the density gradient can be measured as the absolute value of the $b$ parameter.

$$
\log \left(U_{i}\right)=a+b D_{i}+e_{i} .
$$

This empirical specification has become very common, provided that the complex non-linear dynamic predicted by the theoretical model is simplified into a linear model to be estimated with common methodologies. In

\footnotetext{
${ }^{1} \mathrm{An}$ analysis of the causal relationship would in fact require taking into account more complex dynamics closely related to the characters of the agriculture and to the different uses of agricultural land across the whole territory and is definitely beyond the scope of this work.

${ }^{2}$ http://www.cartografia.regione.lombardia.it/geoportale.
} 
Equation (1) $U_{i}$ is the urban density, in this case the ratio of urbanized to total area while $D_{i}$ is the geographical distance separating the municipality from the CBD (assumed to be the main city in the province). Finally $a$ is the estimate of the log of urbanization density in $\mathrm{CBD}$ and $e_{i}$ is the stochastic disturbance.

Following this stream of literature, this work is concerned with estimation of density gradients for the provinces in the Lombardy region. The availability of a unique data source at the regional level allows the comparison of results and, hence, of the different urban structures dominating urbanization patterns in the provinces of Lombardy. For the purpose of our empirical analysis, the estimated density gradients are used, in a second step, to relate urban structure to land use and land take.

Concerning estimation of the density gradient, a common problem in cross sectional studies is the violation of the independence hypothesis made about the error term (Anselin, 1988a, 1988b). This is particularly the case of urbanization density, since land use decisions are known to be affected by external environmental conditions which are usually unobservable and therefore omitted, causing spatially related regression residuals. Based on Anselin's works, correction can be implemented by either assuming that the dependent variable follows a mixed regressive-spatial autoregressive process (Spatial Lag model) or by allowing a spatial structure in the error term (Spatial Error model). In the specific case of density gradient estimation McMillen (2003) has shown that the Spatial Error specification is to be preferred provided that spatially auto-correlated residuals are likely caused by the omission of information related to neighbourhood characteristics.

The model in Equation (1) is modified accordingly and the final specification is expressed as follows:

$$
\left\{\begin{array}{l}
\log \left(U_{i}\right)=a+b D_{i}+e_{i} \\
e_{i}=\lambda W e_{i}+u_{i}
\end{array}\right.
$$

The $W$ matrix in Equation (2) is a row-standardized contiguity matrix expressing the contiguity relationships between municipalities in the same province. The contiguity relationships are defined using the threshold distance criterion, according to which municipalities are said to be neighbours if separated by a distance which value is below a pre-determined threshold. By time to time the threshold at the provincial level is defined in a way to allow each municipality to have at least one neighbour.

\section{Results}

Estimation results based on Equation (2) are summarized in Table 1. Results are obtained by using the urban to total ratio of land as a proxy of urbanization density. Since the largest part of related literature makes use of population density to proxy urbanization density (Baumont et al., 2004; Rodríguez-Gámez \& Dall'erba, 2012), our result are also replicated using population density to ensure consistency with previous literature. These results are not shown but they are available upon request to the authors.

Model parameters have been estimated for both the available years in the dataset, 1999 and 2007. The coefficient $a$, the model intercept, is to be interpreted as the log of urbanization density in the main municipality. Results, in first and fourth columns of Table 1, indicate a high value of the parameter in the cases of Milano, Monza, Varese, Como and Bergamo. This suggests the good predictive capacity of the model. As a further indication of the model capacity to fit the data, the estimated values of 2007 are always larger than those in 1999. This is coherent with evidence that average share of urbanized area has increased over time in all these cities.

By focusing the attention to the coefficient $b$ it is possible to observe that results largely confirm the model's prediction. The expected value of the coefficient is in fact negative, assuming a distance decay effect. Estimates show that this is the case in a majority of municipalities, with the exclusion of Cremona, where such a relationship seems inverted and of Lecco, Mantova and Sondrio, where the estimated coefficient is not significant.

Both in terms of coefficient slopes and statistical significance, the relationship between urbanization density and distance from CBD is unchanged comparing 1999 and 2007. In both years, high density gradients appear in the cases of Bergamo, Brescia Como and Varese while especially low values appear in Milano, Lodi and Monza and Brianza.

Finally, for what concerns the spatial autocorrelation coefficient $\lambda$, this is always positive and significance with the only exception of Mantova. Based on existing evidence, results in this empirical analysis confirm the prominence of spatial relationships for the urbanization process. It is possible to infer that urbanization pattern at the municipality level is affected also by forces operating at a larger spatial scale. 
Table 1. CBD Estimates (1999 and 2007) based on the share of urbanized area.

\begin{tabular}{|c|c|c|c|c|c|c|}
\hline \multirow[t]{2}{*}{ Province } & \multicolumn{3}{|c|}{1999} & \multicolumn{3}{|c|}{2007} \\
\hline & $a$ & $b$ & $\lambda$ & $a$ & $b$ & $\lambda$ \\
\hline \multirow[t]{2}{*}{ BERGAMO } & $2.534^{* * *}$ & $-0.124^{* * *}$ & $0.744^{* * *}$ & $2.629^{* * * *}$ & $-0.124^{* * *}$ & $0.754^{* * *}$ \\
\hline & (5.537) & $(-6.422)$ & (13.143) & (5.581) & $(-6.241)$ & (13.699) \\
\hline \multirow[t]{2}{*}{ BRESCIA } & $0.764^{* *}$ & $-0.065^{* * *}$ & $0.727^{* * *}$ & $0.878^{* * * *}$ & $-0.065^{* * *}$ & $0.741^{* * * *}$ \\
\hline & (1.925) & $(-5.7)$ & (12.346) & (2.116) & $(-5.455)$ & (13.037) \\
\hline \multirow[t]{2}{*}{ СOMO } & $2.347^{* * *}$ & $-0.108^{* * *}$ & $0.71^{* * * *}$ & $2.425^{* * *}$ & $-0.109^{* * *}$ & $0.708^{* * * *}$ \\
\hline & $(5.474)$ & $(-5.335)$ & (11.926) & (5.637) & $(-5.38)$ & (11.807) \\
\hline \multirow[t]{2}{*}{ CREMONA } & $1.172^{* * * *}$ & $0.024^{* * * *}$ & $0.521^{* * * *}$ & $-1.064^{* * *}$ & $0.25^{* * * *}$ & $0.509^{* * * *}$ \\
\hline & $(4.264)$ & (2.599) & (5.373) & $(-4.004)$ & (2.843) & (5.171) \\
\hline \multirow[t]{2}{*}{ LECCO } & 0.28 & -0.006 & $0.784^{* * * *}$ & 0.284 & -0.001 & $0.787^{* * * *}$ \\
\hline & (0.289) & $(-0.105)$ & (12.396) & $(0.295)$ & $(-0.017)$ & (12.587) \\
\hline \multirow[t]{2}{*}{ LODI } & 0.28 & $-0.029^{* * *}$ & 0.166 & $0.434^{* *}$ & $-0.03^{* * *}$ & $0.21^{*}$ \\
\hline & (1.269) & (2.345) & (1.273) & $(1.851)$ & (2.278) & (1.65) \\
\hline \multirow[t]{2}{*}{ MANTOVA } & $1.364^{* * *}$ & 0.011 & 0.046 & $-1.145^{* * *}$ & 0.01 & 0.059 \\
\hline & (6.725) & $(1.362)$ & $(0.299)$ & $(-5.42)$ & (1.16) & $(0.386)$ \\
\hline \multirow[t]{2}{*}{ MILANO } & $1.682^{* * *}$ & $-0.035^{* *}$ & $0.851^{* * *}$ & $1.805^{* * *}$ & $-0.035^{* *}$ & $0.846^{* * *}$ \\
\hline & (2.533) & $(-1.872)$ & (10.151) & (2.796) & $(-1.896)$ & (9.848) \\
\hline \multirow[t]{2}{*}{ MONZA E BRIANZA } & $2.344^{* * *}$ & -0.033 & -0.079 & $2.403^{* * * *}$ & -0.03 & -0.114 \\
\hline & $(10.314)$ & (1.595) & $(-0.395)$ & $(10.935)$ & $(-1.529)$ & $(-0.559)$ \\
\hline \multirow[t]{2}{*}{ PAVIA } & $0.482^{* * *}$ & $-0.048^{* * *}$ & $0.489^{* * *}$ & $0.621^{* * * *}$ & $-0.05^{* * *}$ & $0.485^{* * *}$ \\
\hline & $(2.144)$ & $(-5.58)$ & (6.104) & $(2.726)$ & (5.67) & $(6.022)$ \\
\hline \multirow[t]{2}{*}{ SONDRIO } & $-1.708^{* * *}$ & -0.039 & $0.507^{* * *}$ & $-1.553^{* * *}$ & -0.04 & $0.518^{* * *}$ \\
\hline & $(-2.315)$ & $(-1.517)$ & $(3.82)$ & $(-2.057)$ & $(-1.55)$ & (3.97) \\
\hline \multirow[t]{2}{*}{ VARESE } & $1.898^{* * *}$ & $-0.06^{* * *}$ & $0.543^{* * *}$ & $1.953^{* * *}$ & $-0.06^{* * *}$ & $0.546^{* * *}$ \\
\hline & (5.385) & $(-2.725)$ & $(6.414)$ & $(5.505)$ & $(2.704)$ & $(6.481)$ \\
\hline
\end{tabular}

Notes: z-stat in parenthesis. ${ }^{* * *},{ }^{* *}$ and ${ }^{*}$ denote significance at $99 \%, 95 \%$ e $90 \%$ respectively.

Once the density gradient, a summary measure of the compactness of cities, has been estimated, it is possible to construct a relationship between land use (the urbanized to total land ratio in 1999), land take (variation in urbanized to total land ration between 1999 and 2007) and urban structure (compactness). The purpose of this part of analysis is to see whether spatial structure can affect land use and its change. The three measures have been plotted together and the result is presented in the Figure 1.

In the vertical axis it is indicated the average (at the provincial level) land take between 1999 and 2007, while average land use (at the provincial level) is indicated in the horizontal axis. Again, based on average data, the provinces of Milano, Monza and Brianza, and to a lower extent also Como, Bergamo, Lecco and Varese, exhibit a high value of land use. By the opposite the highest land take has happened in provinces of Mantova, Lodi and Cremona, and in Milan to a lower extent.

The negative line has been obtained by interpolation of average data. Immediately the relationship between land take and land use appears negative, meaning that a large land take has characterized areas with lower scarcity of land. In fact, the phenomenon of land use change and hence reconversion of land use from agriculture to urban, is a character of areas in which urbanization density was lower in 1999.

In the figure, the dimension of the circle associated to each province represents the value of the density gradient previously estimated. The larger the circle, the more compact is the urban spatial structure.

Provided the negative evidence between land take and land use, it is worth paying attention to the fact that more compact urban structures have generated a lover than expected value of land take. This appears clearly by noting that provinces where the density gradient is high reported values of land take lower or at least equal to the value expected from the negative relationship. In the case of territories where land take was initially high, this is the case of Bergamo, Como and Varese, which are located under the black line in the figure. By the opposite Milano and Monza and Brianza are located above the line. In the case of territories where land take was initially 


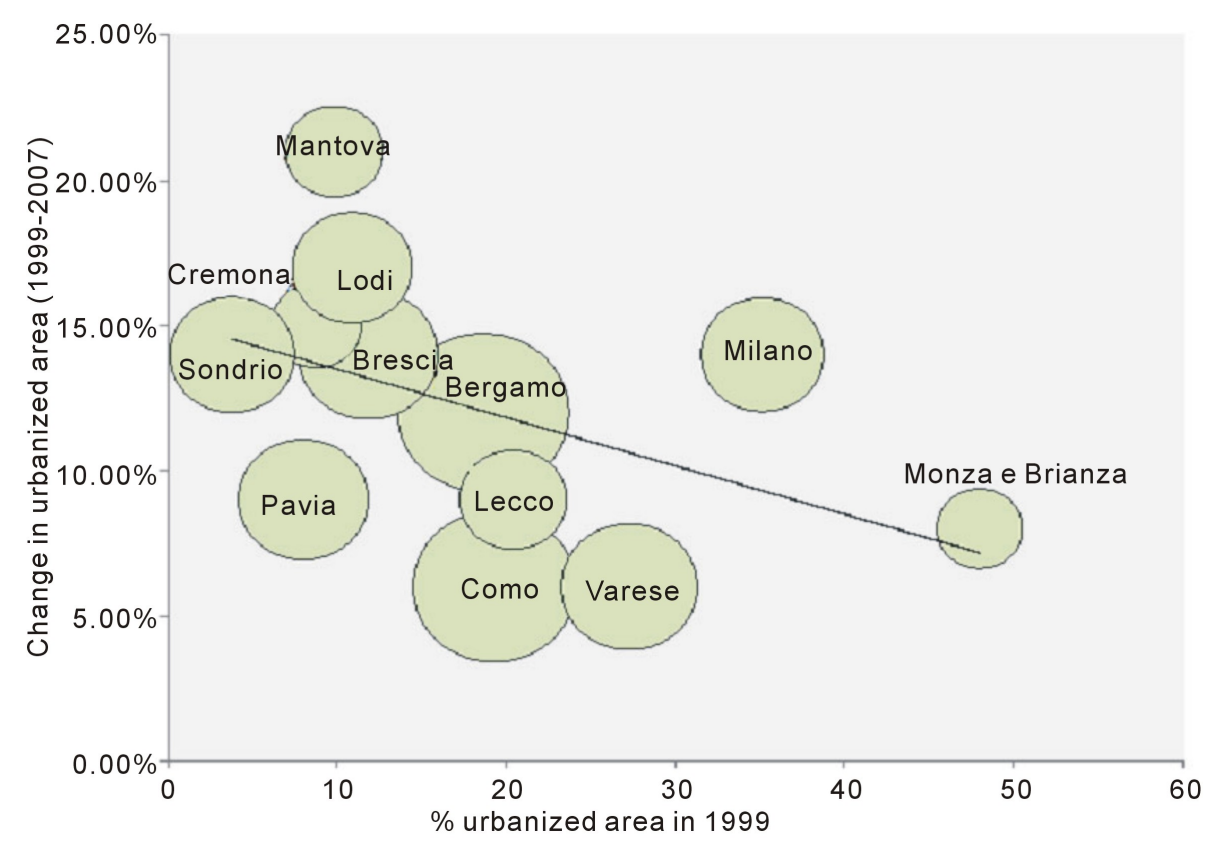

Figure 1. Land use, land Consumption and compactness of urban spatial structure.

low, this is the case of Pavia, which is below the line. By the opposite Cremona, Lodi and Mantova are above the line.

\section{Conclusions}

This empirical work has been concerned with the relationship between land use, land take and urban spatial structure. The issue is of particular relevance for agricultural policies to the extent that a correct use of land, scarce by definition, represents nowadays a necessary condition for the effective implementation of sustainable rural development programs. Development cannot be considered as sustainable if economic and population growth subtracts resources to agriculture, hence impeding rural development. Subtraction of resources to agriculture is a central issue in the debate about the future of agricultural and rural policies in Europe. In particular, given that economic growth requires a certain degree of urban development, which urban structure is more effective with respect to the objective of preserving land?

In an attempt to provide a different viewpoint on the issue, this paper presents empirical analysis on the relationship between urban spatial structure and land use/take. Differently from the traditional approach to the territorial analysis of urbanization, based on multivariate statistical analysis on a number of different indicators, this work focuses on a single variable (urbanized area) for the territorial analysis. This variable is related to the urban spatial structure, as measured by the compactness degree of the urbanized area within the territory of the province.

To describe the urbanization pattern, a density gradient is estimated, following the empirical literature on CBD. A higher value of the density gradient identifies a more compact urban spatial structure while low values indicate sprawl.

The scene pictured by the result of the analysis, using data for 1999 and 2007 is the following. Urban agglomerations structured in a compact manner around a single economic centre have prevented excessive consumption of agricultural land through its conversion for urbanization purposes. This general result need to be further declined considering the different levels of urbanization in the region. Hence, in the most urbanized part of the region, territories characterized by urban sprawl such as Milano and Monza e Brianza, have experienced a larger than expected land take while a lower than expected land take has been noted in more compact cities.

\section{Acknowledgements}

The research has been financed by the Lombardy Region (IT) under the project AGAPU (Analysis and Gov- 
ernment of Peri-Urban Territories).

\section{References}

Alonso, W. (1964). Location and Land Use. Toward a General Theory of Land Rent. Cambridge: Harward University Press. http://dx.doi.org/10.4159/harvard.9780674730854

Anania, G., \& Tarsitano, A. (1995). Tecniche di analisi statistica multivariate per l'interpretazione dei sistemi agricoli territoriali in Italia, In G. Cannata, (Ed.), I sistemi agricoli territoriali italiani degli anni ’90. Cosenza: Rubbettino.

Anania, G., \& Tenuta, A (2008). Ruralità, urbanità e ricchezza dei comuni italiani. Rome: QA-Rivista dell'associazione Rossi-Doria.

Anselin, L. (1988a). Spatial Econometrics Methods and Models. Boston, MA: Kluwer Academic Publisher. http://dx.doi.org/10.1007/978-94-015-7799-1

Anselin, L. (1988b). Lagrange Multiplier Test Diagnostic for Spatial Dependence and Spatial Heterogeneity. Geographical Analysis, 20, 1-17. http://dx.doi.org/10.1111/j.1538-4632.1988.tb00159.x

Asciuto, A., Di Franco, C. P., \& Migliore, G. (2008). Analisi della ruralità in una regione ad obiettivo converenza II: il caso della regione Sicilia. XLV Congress of the Italian Society of Agricultural Economics.

Baumont, C., Ertur, C. \& Le Gallo, J. (2004). Spatial Analysis of Employment and Population Density: The Case of the Agglomeration of Dijon 1999. Geographical Analysis, 36, 146-176. http://dx.doi.org/10.1111/j.1538-4632.2004.tb01130.x

Brueckner, J.K. (2000). Urban Sprawl: Diagnosis and Remedies. International Regional Science Review, 23, $160-171$. http://dx.doi.org/10.1177/016001700761012710

Cannata, G. (1989). I sistemi agricoli territoriali italiani. Milano: Franco Angeli.

Cannata, G. \& Forleo, M.B. (1998). I sistemi agricoli territoriali delle regioni italiane. Anni novanta CNR, Campobasso: Progetto finalizzato RAISA (Ricerche Avanzate per Innovazioni del Sistema Agricolo).

Cannata, G. (1995). I sistemi territoriali agricoli italiani degli anni ’90. Cosenza: Rubbettino.

Esposti, R. (2000). Problemi e risorse per lo sviluppo rurale. In A. Arzeni, R. Esposti, A. Solustri, \& F. Sotte (Eds.), Il sistema agricolo ed alimentare nelle Marche. Rapporto 2000. Milano: Franco Angeli.

European Commission (2012). The Common Agricultural Policy a Partnership between Europe and Farmers. Luxembourg: Publications Office of the European Union.

Gallego, F. J. (2004). Mapping Rural/Urban Areas from Population Density Grids. Italy: Institute for Environment and Sustainability, JRC-EC, ISPRA.

McMillen, D. P. (2003). Spatial Autocorrelation or Model Misspecification? International Regional Science Review, 26, 208-217. http://dx.doi.org/10.1177/0160017602250977

McMillen, D. P. (2006). Ch 8 Testing for Monocentricity. In R. J. Arnott, \& D. P. McMillen (Eds.), A Companion to Urban Economics. Oxford, UK: Blackwell Publishing Ltd.

Mills, E. S. (1967). An Aggregative Model of Resource Allocation in a Metropolitan Area. The American Economic Review, 57, 197-210.

MIPAAF (2011). Costruire il futuro: Difendere l'agricoltura dalla cementificazione.

Muth, R. F. (1969). Cities and Housing: The Spatial Pattern of Urban Residential Land Use. Chicago and London: The University of Chicago Press.

Pareglio, S., \& Pozzi, F. (2013). Analisi e caratterizzazione dei sistemi agricoli e territoriali della Lombardia. In Analisi $e$ Governo dell'Agricoltura Periurbana-Rapporto finale del progetto di ricerca AGAPU. Milan: Fondazione Lombardia per l'Ambiente.

Pareglio, S. (2013). The Case for Policy Intervention in Land Use Change: A Critical Assessment. Italian Journal of Agronomy, 8, 217-223.

Paulsen, K. (2012). Yet even More Evidence on the Spatial Size of Cities: Urban Spatial Expansion in the US, $1980-2000$. Regional Science and Urban Economics, 42, 561-568. http://dx.doi.org/10.1016/j.regsciurbeco.2012.02.002

Rodríguez-Gámez, L., \& Dall'erba, S. (2012). Spatial Distribution of Employment in Hermosillo, 1999-2004. Urban Studies, 49, 3663-3678. http://dx.doi.org/10.1177/0042098012448552

Vard, T., Willems, E., Lemmens, T., \& Peters, R. (2005). Use of the CORINE Land Cover to Identify the Rural Character of Communes and Regions at EU Level. In: Trends of Some Agri-Environmental Indicators of the European Union, EUR 21669 EN 220. Luxembourg: Office for Official Publications of the European Communities. 
Scientific Research Publishing (SCIRP) is one of the largest Open Access journal publishers. It is currently publishing more than 200 open access, online, peer-reviewed journals covering a wide range of academic disciplines. SCIRP serves the worldwide academic communities and contributes to the progress and application of science with its publication.

Other selected journals from SCIRP are listed as below. Submit your manuscript to us via either submit@scirp.org or Online Submission Portal.
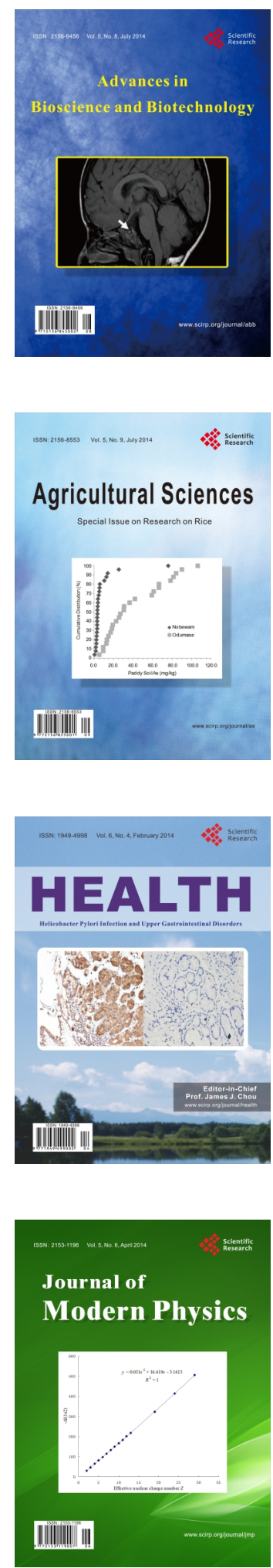
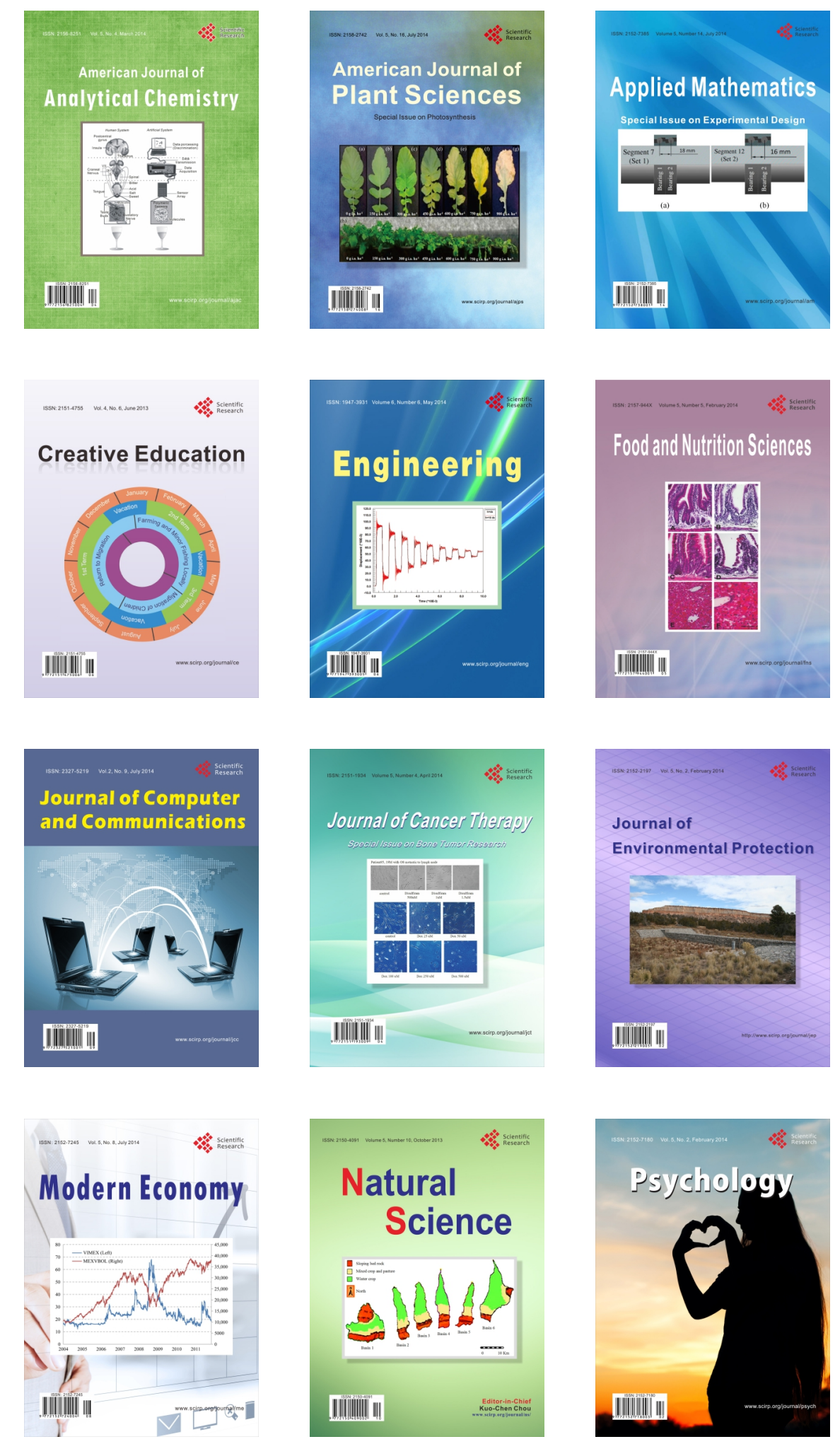